\title{
Autoexpresión y privacidad de los universitarios en las redes sociales. Los estudiantes de la Universidad del País Vasco como caso de estudio
}

\section{Self Expression and Privacy of University Students in Social Networks. Students at the University of the Basque Country as a case study}

\author{
Elena Olábarri Fernández. Universidad del País Vasco
}

Sergio Monge Benito. Universidad del País Vasco

Recibido: 1-XII-2010 - Aceptado: 13-VI-2011

Resumen:

El objetivo de nuestro análisis es el estudio de las dinámicas de relación que se generan en las redes sociales. Los jóvenes universitarios usuarios de redes sociales son el sector de población que hemos elegido para nuestro análisis ya que son los primeros adoptantes de las mismas y aquellos que con mayor facilidad están integrándolas en sus relaciónes. Mediante la realización de dos grupos de discusión y una encuesta autoadministrada a 544 estudiantes de la Universidad del País Vasco, se analiza qué diferentes imágenes tienen de las dos redes líderes (Facebook y Tuenti), al tiempo que se profundiza en el conocimiento de los mecanismos de relación que éstas generan. Los resultados muestran dos redes sociales con muy diferente imagen de marca, así como universitarios sensibles a la exhibición de su intimidad y que no se cuestionan la credibilidad de los contenidos de los perfiles.

Palabras clave:

Redes sociales; universitarios; imagen de marca; intimidad; indicadores perceptivos; credibilidad.

Abstract:

Our analysis aims to study the relationship dynamics that are generated in social networks. We have focused our study on university students because they are the first adopters of social networks and the ones that are integrating them most easily in their dynamics of relation. By forming two groups of discussion and carrying out a self-administered survey to 544 students at the University of the Basque Country we analyze the images associated to the two leading networks (Facebook and Tuenti) as we explore the knowledge of the mechanisms of relation that these generate. The results obtained show two social networks with a very distinct brand image as well as university students that are very sensitive to the exhibition of their intimacy and who do not question the credibility of the profiles content.

Keywords:

Social Networks; University Students; Brand Image; Intimacy; Perceptive Indicators; Credibility. 


\section{Introducción}

Los resultados del presente artículo corresponden a una investigación más amplia sobre los universitarios y las redes sociales ${ }^{1}$. Parte de los resultados de esta investigación han sido publicados previamente en un artículo en la Revista Latina de Comunicación Social (Monge, Olabarri, 2011). Lo que se puede leer a continuación son los resultados de esta investigación en cuanto a las cuestiones autoexpresivas y de privacidad, aunque se reproducen algunos datos introductorios que también aparecían publicados en el artículo previo.

Se ha investigado cómo los medios de comunicación se han lanzado ya a intentar utilizar las redes sociales (Noguera, 2010), qué nuevos perfiles profesionales y cambios se están produciendo (Flores-Vivar, 2009), cuáles son las representaciones mediáticas que generan (Bacallao Pino, 2010) o cuáles parecen ser las razones por las que Facebook tiene un crecimiento mayor que Tuenti (García, 2010). Si bien hace unos años nos preguntábamos si serían un fenómeno pasajero o un cambio significativo en nuestra forma de estar en contacto (Fernández, 2008), hoy en día ya nadie duda que las redes sociales están aquí para quedarse y que ocupan cada vez un lugar más importante en nuestro modo de comunicarnos, sobre todo entre la población más joven.

Las redes sociales han experimentado un considerable crecimiento en España en los últimos dos años, especialmente en lo que se refiere a las dos líderes: Tuenti y Facebook. Según el observatorio de The Cocktail Analysis $(2008,2010)$, entre 2008 y 2009 el porcentaje de la población internauta española usuaria de estas dos redes se incrementó del 12\% al 33\% en el caso de Tuenti y del 13\% al 64\% en el caso de Facebook. Esos porcentajes se incrementan aún más, a 35\% y 78\% cuando revisamos los resultados de 2010 (The Cocktail Analysis, 2011)

La distinción entre los riesgos que conllevan y las oportunidades que ofrecen redes como Facebock, Twiter, MySpace o Tuenti está lejos de ser clara. Los estudios llevados a cabo por Livingstone (2007-2008-2010) con jóvenes y adolescentes ponen de manifiesto como tanto las oportunidades como los riesgos relacionados con internet se intensifican en las redes sociales. Estas redes ofrecen a cualquiera la posibilidad de abrir su intimidad a círculos amplios de personas, lo que ha supuesto que la distinción entre espacio público y privado se diluya. El marco de relaciones creado por ellas no conoce líneas divisorias, convirtiéndose en un fenómeno de interrelación entre los usuarios de Internet que genera una estructura propicia para que los

\footnotetext{
1 Artículo resultado del proyecto de investigación: “Universitarios y redes sociales: nuevas formas de relación online”, financiada por la Universidad del País Vasco 2010-2011.
} 
sujetos muestren aspectos de su vida. Las páginas de inicio de redes como Tuenti o Facebook son un rosario de pequeñas dosis de vida íntima donde mostrar reflexiones, comentarios, fotos, etc..., bastante pensadas, y dirigidas no solo al reducido círculo de los más cercanos, también a anónimos desconocidos. En ellas, los individuos exponen fragmentos de su ámbito privado que antes del surgimiento de estas nuevas tecnologías no sucedía. Esto está provocando el debilitamiento de la intimidad y la aparición de un nuevo término que se ha dado en llamar "extimidad", algo así como hacer visible la intimidad, donde lo público y lo privado se confunden (Jacques A. Millar, 1985). Si bien este término lo acuñó Jacques Lacan, nuestro significado difiere del otorgado por el psicoanalista francés, refiriéndose a aquello que siendo muy íntimo y familiar se convierte en algo radicalmente extraño.

En Internet contamos lo que queremos contar. El usuario de la red social decide qué parte de su intimidad quiere hacer pública. Ese "saber mostrarse" en palabras de Paula Sibila (2008) es un valor indiscutible porque parece garantizar la propia existencia. Mostrar la intimidad confirma que existimos ${ }^{2}$. Estar permanentemente informando a otros de lo que estamos haciendo, en el fondo significa la necesidad de garantizar nuestra identidad en cada momento. En una cultura de la visibilidad o "sociedad del espectáculo" como la llamó Guy Debord (1967), uno es lo que se ve de él. Se podría decir que existe pánico al anonimato. Hoy en día hay que mostrarse y hay que intentar "ser visto" para "ser alguien". La periodista Llucia Ramis (2010) indaga sobre la tiranía que ejercen las nuevas tecnologías y pone de manifiesto la influencia de Internet en las relaciones personales que se producen fuera de la red. A su juicio, en Facebook, la gente más que voyeur es exhibicionista.

En las redes sociales, cada detalle del perfil es resultado de un proceso de reflexión por parte del autor en relación a la decisión de qué elementos incluir. Así, al examinar los contenidos de los perfiles se observa que la principal creación de sus autores es, casi siempre su yo. Si bien han sido varios los investigadores que han analizado las formas de construir identidades online a partir de los recursos que ofrece la red, obviamente más maleable que el cara a cara, recientes investigaciones (Weisbuch, Ivcevic y Ambady, 2009; Mitja D. Back et al., 2010) han concluido que existe consistencia entre la impresión que nos formamos sobre otros en base a la interacción cara a cara y la formada estudiando por ejemplo, su página web o su perfil de Facebook. De manera que la información que contiene el perfil expresa características reales del autor.

Como apunta Leonardo Cervera (2009). “desde siempre, los más jóvenes han sentido la necesidad de socializar, hacer amistades, flirtear, etc... Cuando te abres a los demás, como ocurre en Internet, buscas esa función que siempre ha cumplido el amigo íntimo y que ahora ha ampliado el abanico. Antes, esto se hacía exclusivamente en el "mundo real"; ahora, el "mundo virtual" ofrece muchas ventajas, ya que en las redes sociales pueden relacionarse cuando les viene bien y mostrar una imagen de sí mismos, que pueden modificar conforme cambian sus gustos y sus aficiones". 
Vazire, S y Gosling S. (2004) han estudiado el manejo de impresiones y el control de indicadores de la imagen en la red. Su premisa es que en el entorno web presentamos aquellos elementos que mejor nos describen, de manera que las personas se guían por el deseo de que su imagen pública coincida con su yo deseado. En el mismo sentido, investigadores como Manago, Gram, Greenfield \& Salimkhan (2008) consideran que los perfiles son utilizados para crear y comunicar una imagen idealizada del yo. Hancock \& Toma (2009) en un estudio sobre las fotografías online ponen en relación, por un lado, el deseo de ser atrayente $y$, por otro, las exigencias de autenticidad. Encontraron que la discrepancia entre estos dos elementos es, en el caso de las mujeres superior al de los hombres, con exactamente tres veces más inexactitudes. Lo más curioso es que los hombres se percatan de su discrepancia, lo que no ocurre en el caso de las féminas (no se daban cuenta de la discrepancia entre la realidad y la imagen fotográfica retocada).

Autores como Weisbuch, Ivcevic y Ambady (2008) observan cómo muchas actividades sociales importantes que hasta ahora tenían un hueco en el mundo real, quedarán relegadas en éste y adquirirán protagonismo en Internet. Por ello, todo el conocimiento adquirido acerca de la formación de primeras impresiones, la percepción y otros tópicos han de ser revisados en la nueva realidad social.

\section{Objetivos de la investigación}

Nuestro análisis pretende centrarse en las dinámicas de relación que mantienen los jóvenes de la Universidad del País Vasco en las redes sociales. La investigación se ciñe al estudio de dos redes sociales, Tuenti y Facebook, por ser las de mayor frecuencia de uso entre los jóvenes universitarios españoles (35\% y 78\% de los internautas españoles, respectivamente, tienen cuenta y las usan habitualmente según la tercera oleada del Informe del Observatorio de Redes Sociales de The Cocktail Análisis 2011). Los datos sobre Facebook, a nivel internacional, la convierten en la red social líder indiscutible en cuanto al número de perfiles y penetración global. No obstante, España presenta una casuística particular con la existencia de la red social Tuenti, perteneciente al grupo de comunicación Telefónica. Dentro del segmento de edad 16-25 años, la penetración de Tuenti está entre el 75\% y el 66\% (The Cocktail Analysis, 2011).

La relevancia de las redes sociales es difícil de negar en un público de interés estratégico como es el sector de población que hemos elegido para nuestro estudio (jóvenes universitarios), ya que los jóvenes son los primeros adoptantes de las redes sociales (Facebook comenzó como una red exclusivamente universitaria). También son los que con mayor facilidad están integrándolas en sus dinámicas de relación, manteniendo un alto grado de uso de las mismas y siendo relativamente accesibles para la investigación. Aunque es pronto para asegurarlo, dado que las redes podrían ser una moda pasajera (tienen apenas tres años de vida 
en nuestro país), los jóvenes son también la base de usuarios futuros de las redes y es previsible que sus costumbres y visiones sobre las mismas tengan un considerable impacto.

A partir de distintas fuentes secundarias tenemos cierta información sobre el uso de las redes sociales. Conocemos que el porcentaje de usuarios que se conecta diariamente a ellas es muy elevado, rondando entre el 55\% (The Cocktail Analysis, 2010: 7) y el 61\% (IAB, 2009:8), con resultados de 58\% y 62\% para Facebook y Tuenti respectivamente en la oleada de 2010 (The Cocktail Analysis, 2011), por lo que podemos concluir que son medios de consumo muy frecuente. En cuanto a las principales motivaciones para usar redes sociales (The Cocktail Analysis, 2010: 21) están el mantener contacto con los amigos y conocidos (61\%), entretenerse (51\%), localizar a viejos amigos o conocidos (36\%), obtener información de fiestas o eventos (28\%) y hacer nuevos amigos (20\%).

No obstante se plantean más preguntas sobre las formas de uso e intensidad que se escapan de lo contenido en los estudios recientes. Por ello esta investigación se centrará en los siguientes objetivos concretos:

- $\quad$ Conocer la imagen de las dos redes sociales líderes, Tuenti y Facebook. Si bien son bastante similares en cuanto a funcionalidades y propósito general: ¿Encuentran los jóvenes diferencias entre ellas? ¿ Difiere la imagen que tienen de cada red social? ¿En qué sentido?

- $\quad$ Estudiar las redes sociales como un contexto de autoexpresión. Este objetivo implica indagar en el tipo de reflexión que hacen a la hora de subir contenidos sobre su propia persona a la red: ¿Existe autocensura? ¿Qué acciones llevan a cabo para proteger su información?

- $\quad$ Conocer cuáles son los elementos de los perfiles que actúan como indicadores perceptivos (fotografías, textos, etc).

- Descubrir el grado de credibilidad asignada a la información publicada, así como la importancia concedida a la misma.

\section{Metodología}

La aproximación al objeto de estudio se ha llevado a cabo desde una metodología combinada cualitativa/cuantitativa. En una primera fase se realizaron dos grupos de discusión, los días 8 y 23 de febrero de 2010. En cada grupo participaron 7 alumnos usuarios de redes sociales. Para ello se acudió a las aulas de las distintas carreras de Comunicación (Periodismo, Publicidad, Comunicación Audiovisual, Sociología y Ciencia Política), tanto del primer ciclo académico como del segundo y se solicitó la colaboración de alumnos 
que fueran usuarios de alguna de las dos redes y que invirtieran en ellas al menos cuatro horas semanales. La colaboración de los participantes fue altruista. Más de la mitad de los seleccionados también participaban en otras redes sociales.

No hubo diferencias significativas en los contenidos de ambos grupos, por lo que se decidió proseguir a la siguiente fase.

Los temas tratados en las reuniones versaron sobre las siguientes cuestiones:

- $\quad$ Redes sociales en las que tienen sus perfiles y el uso que hacen de las mismas.

- $\quad$ La preocupación por la gestión de la visibilidad.

- Importancia que conceden a la privacidad.

- Grado de preocupación por la información que suben a las redes sociales.

- $\quad$ Identificación de indicadores de calidad / falsedad de los perfiles.

El objetivo de los mismos fue, por un lado, asegurar que los investigadores compartían terminología y perspectivas con los sujetos de estudio. Los grupos de discusión también nos dieron la posibilidad de tratar los temas objeto de estudio desde una perspectiva más abierta e incluso nuevos puntos de vista desde los que entender e interpretar la cuestión. Y fundamentalmente, la información cualitativa procedente de estas dos reuniones, dió como resultado el diseño definitivo de la encuesta.

Una encuesta piloto (20 encuestas) nos ayudó a realizar correcciones de orden formal. Posteriormente se preparó un cuestionario autoadministrado que fué enviado vía email a todos los alumnos (6.700) de tres facultades de la Universidad del País Vasco: Facultad de Ciencias Sociales y de la Comunicación, Facultad de Ciencia y Tecnología y La Escuela Técnica Superior de Ingeniería ${ }^{3}$. La selección de las facultades obedeció al deseo de que la muestra no estuviese contaminada por el tipo de estudios de los universitarios; de ahí la selección de alumnos tanto del ámbito de las ciencias sociales como tecnológico. (Ver en el cuestionario en el anexo 2).

\section{Muestra}

La muestra de nuestro estudio la forman los estudiantes de la Universidad del País Vasco. La recogida de datos se realizó durante los meses de mayo y junio de 2010. La encuesta fue distribuida a través del servi-

3 El número total de alumnos matriculados en el curso 2010-11 en la Universidad del País Vasco ascendía a 40.000.

$94 \mid n^{\circ} 13$ | doxa.comunicación 
dor de la universidad a los correos electrónicos de todos los alumnos matriculados en estas facultades (6.700 alumnos). Iba acompañada de un email de presentación de los investigadores solicitando su participación. Con anterioridad se envió otro email a los delegados de todos los cursos, así como una llamada telefónica informándoles personalmente del contenido de la investigación y solicitando su colaboración para informar y animar a la participación de sus compañeros.

Se recogieron un total de 652 encuestas (10\% de las enviadas). Sin embargo, la muestra final quedó fijada en 544 encuestas válidas (el $84 \%$ del total de encuestas recibidas). Este era el número de alumnos que tenían cuenta en Tuenti y/o Facebook. El estudio, con una muestra de 544 casos supone un error muestral del $4,5 \%$ con un nivel de confianza del 95,5\% y en la hipótesis de máxima variabilidad, es decir p=q= 50\%.

Del total de las encuestas válidas recogidas, 356 (65\%) las contestaron mujeres y 188 (35\%) hombres. Estos datos, frente a la media de alumnas en la UPV (56\%), nos dan una ligera sobre-representación de las mujeres de la muestra en relación a las proporciones de la universidad. Esta diferencia de porcentajes se puede explicar en el hecho constatado por distintos infomes nacionales (Sánchez Burón, Fernández Martín, 2010: 8; Informe The Cocktail Analysis 2009: 8 y 2010: 13; Bringué y Sábada, 2009: 17; EU Kids Online 2011: 34) en los que se evidencia cómo el uso de las redes sociales es superior (entre un 8\% y un 12\%) entre las mujeres.

En relación a la edad, el 81,13\% de la muestra se encuentra entre los 18 y los 23 años, la franja de edad universitaria más habitual.

Todos los datos que se ofrecen a continuación provienen de los 544 encuestados que declararon tener cuentas en las redes sociales.

La muestra tiene limitaciones, ya que se trata de universitarios provenientes de una sola universidad de una región concreta. No obstante, tiene un tamaño apropiado para hacer generalizaciones sobre los estudiantes de la Universidad del País Vasco. Además, los resultados en varios indicadores son coincidentes con las fuentes secundarias que hemos consultado. Sin embargo, entendemos que es aventurado pensar que los resultados se puedan extrapolar al conjunto de los universitarios españoles.

Esto es muy claro en el caso de Cataluña y las Islas Baleares. Por alguna razón desconocida y sorprendente, el estudio “Generación 2.0” detectó que los adolescentes (11-20 años) españoles preferían consistentemente Tuenti sobre Facebook (también es el caso de nuestra muestra universitaria) en todas las Comunidades Autónomas con excepción de Cataluña, dónde el 75,2\% prefería la red social norteamericana frente al 5,1\% que se quedaba con la versión local (Sánchez Burón, Fernández Martín, 2010: 11). También había diferencias significativas en Islas Baleares, si bien mucho menores (24,1\% frente a 67,3\%). 
El análisis de la información se ha realizado mediante tablas de contingencia y la prueba del Chi cuadrado para medir la existencia de relación entre las variables estudiadas.

\section{Análisis de resultados}

\subsection{Sobre la imagen de Tuenti y Facebook}

Parte de la información de este punto ya fue publicada en un artículo anterior (Monge, Olabarri, 2010). Se reproduce aquí por el interés que tiene para introducir los temas que desarrolla el artículo posteriormente. La preferencia de Tuenti sobre Facebook es manifiesta (gráfico 1). El 64,31\% de la muestra manifiesta que Tuenti es su preferido frente al 20,85\% que prefiere Facebook y el 14,84\% que no tiene preferencia (porcentajes similares a los presentados por Bringué y Sábeda, 2009: 17). La preferencia por Tuenti de los universitarios es menos marcada que la de los adolescentes, que se decantan en un 88,5\% por esta red frente al 7,4\% que lo hace por Facebook (Sanchez Burón, Fernández Martín, 2010:11). Es decir, a medida que la edad se incrementa, la preferencia por Tuenti decrece y aumenta la de Facebook. Los datos de nuestra muestra son bastante coincidentes con el estudio "Generación 2.0" en lo que se refiere a los más jóvenes: a los 18 años, por ejemplo, la preferencia por Tuenti aumenta hasta el 82,93\%.

Esta relación de las preferencias con la edad puede explicar que Tuenti tenga una clara imagen de estar participado por gente más joven (84,57\% frente al 3,19\% de Facebook). Ahí puede residir parte de su atractivo para el público más joven, que también la identifica como la mejor herramienta para relacionarse con amigos cercanos (71,63\% frente al 7,09\% de Faceboook) y, en menor medida, la mejor herramienta para relacionarse con conocidos (51,50\% frente al 13,27\%).

No olvidemos que el acceso a Tuenti es por invitación mientras que el registro en Facebook es voluntario y directo. Esto probablemente ha propiciado la construcción de un entorno de relación más cercano, compuesto por amigos de edad similar. En las reuniones de grupo hubo varias declaraciones que apuntaban en esta misma dirección, al señalar que su competidora carecía de esa intimidad: "En mi grupo de amigas las madres tienen Facebook y entonces cuidamos lo que decimos" o "en Facebook está mi madre".

A pesar de todo, la idea de intimidad tampoco es tan fuerte como podríamos suponer. El 43,89\% consideró que Tuenti es un entorno más íntimo en contraposición al 21,95\% que se decidió por Facebook. Existe un buen número de indecisos $(34,16 \%)$ en esta cuestión que consideran que ambas redes ofrecen niveles parecidos de intimidad, por lo que no se puede sacar una conclusión clara, las redes sociales distan de ser 
percibidas como un espacio realmente íntimo a pesar de lo que se esbozaba en una de las fuentes secundarias consultadas previamente (Zed Digital, 2008: 24).

Tuenti también es percibido como una herramienta “más rápida para contar cosas" (52,74\%) que Facebook $(10,27 \%)$. Varias aportaciones ofrecidas por los grupos de discusión sugieren que este factor podría tener que ver con la frecuencia de uso de las redes por parte de los jóvenes universitarios (por ejemplo, "al Tuenti me conecto varias veces al día y a Facebook una vez a la semana"). Los resultados de The Cocktail Analysis (2011) apoyan esta tesis, pero solo levemente: el porcentaje de los que se conectan diariamente es más alto en Tuenti (62\%) que en Facebook (58\%). También podría sugerir que Tuenti es capaz de generar niveles más elevados de compromiso que Facebook (sus usuarios generan más implicación con la herramienta), aunque no disponemos de datos que prueben tales hipótesis. Bien esté relacionado con la sencillez o el manejo intuitivo, bien tenga que ver con la frecuencia de uso o la implicación que genera la herramienta, lo cierto es que la red española tiene una marcada imagen de ser una “herramienta más rápida para contar cosas” que su competidora americana.

En el lado contrario, Facebook es percibida como una herramienta más completa $(77,33 \%)$ que Tuenti $(10,25 \%)$. Varios factores pueden contribuir a esta imagen. En primer lugar, Facebook ofrece a los desarrolladores de software externos a ella la posibilidad de añadir aplicaciones a la plataforma. Por otro lado, Facebook ha tenido tradicionalmente más funcionalidades que Tuenti (grupos, páginas, pestañas en los perfiles...). Esta imagen de red más completa no siempre tiene consecuencias positivas, como algunos entrevistados expresaron durante las reuniones de grupo: "no me entero, entre los jueguitos [...] a mí me mandan y yo, claro, como solo lo utilizo para mandar mensajes y mirar las fotos..."

Facebook también tiene una imagen de mayor formalidad/profesionalidad (69,20\% frente a 6,73\%). La influencia positiva que pueda tener esta asociación de marca es limitada puesto que, como hemos visto, los usos profesionales de las redes quedan bastante abajo en la lista cuando se pregunta a los usuarios por sus motivaciones para adentrarse en ellas (The Cocktail Analysis, 2010: 7).

En otro orden de cosas, hemos visto que Tuenti era considerada la mejor red para mantener contacto con amigos cercanos y conocidos. Por el contrario, Facebook es considerada la red social que utilizarían para estar en contacto con "gente de fuera" (82,62\% frente al 4,79\%). Esto se corresponde con las declaraciones de los grupos de discusión: "Yo tengo Facebook porque viví en Inglaterra un tiempo".

La red social americana tiene un alcance internacional que la española no tiene, así como una enorme base de usuarios fuera de España (400 millones de usuarios activos en todo el mundo). Los estudiantes univer- 
sitarios europeos entablan con cierta frecuencia relaciones con otros universitarios de distintos países gracias a distintos programas de intercambio, el más conocido de los cuales es el programa Erasmus. Facebook "es como más universal" y se utiliza a menudo para mantener relaciones con personas en otros países: "mi hermana por ejemplo vive en el extranjero [...] antes nos mandábamos emails pero ahora lo hacemos todo directamente por Facebook".

La idea de universalidad de la red americana ha quedado reforzada por otro elemento del cuestionario. Cuando se pregunta a la muestra en qué red social "participa más gente", los encuestados se decantan por Facebook en un $65,25 \%$ frente al $21,28 \%$ que lo hace por Tuenti.

Por lo tanto, podemos decir que los estudiantes universitarios distinguen perfectamente entre ambas redes, que tienen muy diferentes asociaciones de marca. Tuenti es más sencilla, más intuitiva, más rápida para contar cosas, más apropiada para relacionarse con amigos y conocidos y, en cierta medida, un espacio más íntimo. Tuenti es, sin duda, la preferida de los estudiantes universitarios.

Por el contrario, Facebook tiene una imagen mucho más universal, profesional, más completa, más apropiada para relacionarse con "gente de fuera" y a la vez tiene una vertiente lúdica y de entretenimiento, muy probablemente impulsada por los juegos a los que da acceso.

\subsection{Las redes sociales como un contexto controlado de autoexpresión}

La exposición de la intimidad es un fenómeno del sujeto contemporáneo. Las redes sociales permiten compartir con otros una especie de diario íntimo, son ventanas de intimidad abiertas a los ojos de los demás, donde se genera una estructura propicia para que los sujetos muestren parcelas de su vida de diversas formas. La simple observación de un perfil nos puede llevar a pensar cómo el día a día de su mentor se exhibe en el escaparate de la red. Ello ha generado un frente de posturas alarmistas, frecuentes en los medios de comunicación que nos presentan a un joven que muestra sin pudor su imagen. Sin embargo, en nuestra investigación hemos podido constatar que tal consideración no es del todo acertada ya que los jóvenes entrevistados ejercitan en su mayoría distintos mecanismos para conservar su privacidad y controlar el acceso de terceros a su perfil.

Observando el gráfico 2 podemos decir que, en conjunto, al 80\% de los jóvenes les preocupa que la información que suben a la red pueda ser utilizada o malinterpretada por terceros. Esta percepción de vulnerabilidad es vivida con intensidad por prácticamente 6 de cada 10 entrevistados. Encontramos una relación positiva y significativa entre la preocupación por esta cuestión y el género ${ }^{4}$. Un $16 \%$ de las uni-

4 Esta relación se ha medido a través del estadístico Chi Cuadrado. La prueba, con dos grados de libertad, ha dado un valor de 1,7405E- 
versitarias admiten no dar importancia a lo que otros hagan con su información, mientras que entre ellos el porcentaje alcanza a uno de cada cuatro $(26 \%)$.

Prueba de esta búsqueda de seguridad es el conjunto de estrategias que ponen en práctica para controlar su imagen (gráfico 3). La gestión de la privacidad la llevan a cabo de forma consciente y activa a través de las posibilidades que ofrecen las propias plataformas. Controlar qué información suben a la red y cambiar las opciones de privacidad para limitar el acceso de terceros a las mismas, concitan el acuerdo de prácticamente la totalidad de los universitarios. Podemos, por tanto, afirmar cómo los jóvenes no son tan impulsivos y tan poco reflexivos en la exhibición de sus contenidos como cabría esperar, sino que los estudian de forma cuidada. En las reuniones de grupo fueron frecuentes frases como: "el entorno está controlado, tú eliges quien forma parte".

Otra práctica mencionada por la mayoría (90\%) consiste en blindar su perfil a la vista de desconocidos. También encontramos en este punto una relación significativa entre género y la acción de blindar el perfil $^{5}$. De igual manera que aparece en estudios europeos (EU Kids Online 2011:36), son las chicas las que con mayor frecuencia configuran un perfil privado en la red social. En sentido contrario, debemos mencionar cómo el número de universitarios favorable a que su perfil sea lo más abierto posible se acerca al 10\%. Una explicación que podemos apuntar es que la percepción de vulnerabilidad puede tener su contrapartida en vivir las redes como plataforma de búsqueda de identidad, que no apunta sólo al centro de cada uno o al reducido círculo de los más cercanos, sino que tiende lazos de relaciones virtuales buscando formas de aprobación.

Si bien las prácticas mencionadas son comunes a casi todos los usuarios de las redes sociales, otras acciones son prácticadas por menor número de universitarios. Así el 85\% de los jóvenes aceptan como amigos solo a personas que conocen. En este punto, nuestros datos coinciden con los obtenidos en una reciente investigación realizada en España sobre los hábitos de los adolescentes en el uso de las redes sociales (Bringué y Sabada 2009: 19) donde los autores constatan que la relación de éstos en la red con personas que desconocen es practicada por aproximadamente el 13\% de los adolescentes españoles.

Las estrategias de protección de la intimidad más pro-activas y directamente relacionadas con el control de contenidos, como pedir a amigos que retiren fotos suyas que no les agradan (60\%), vigilar toda la información que sobre ellos se suben a las redes (57\%) o des-etiquetar fotos suyas que otros han subido y no quieren

10. Aceptando la significatividad cuando resulta menor de 0,0001 con un margen de confianza del 99,5\%.

5 La prueba Chi cuadrado realizada da como resultado, para un grado de libertad, 3,76558E-05. Aceptando la significatividad cuando resulta menor de 0,0001 con un margen de confianza del 99,5\%. 
que sean publicadas (47\%) son las menos practicadas. En todos estos casos, es el colectivo femenino quien las lleva a cabo con mayor frecuencia. En este punto, los resultados obtenidos en una investigación con adolescentes de Bringué y Sábada (2011:201-208) son coincidentes con los nuestros. Los autores concluyen cómo los chicos parecen más arriesgados o más abiertos que las chicas a la hora de colgar información de carácter personal.

La conducta menos frecuente entre los jóvenes (36\%) es retocar fotografías que suben al perfil. Siendo las diferencias en relación al género significativas estadísticamente ${ }^{6}$. Mientras prácticamente 5 de cada 10 universitarias reconoce que las practica, sólo 2 de cada 10 universitarios confiesan practicarla. Socialmente es una conducta que puede resultar menos confesable, sobre todo para ellos.

A la luz de estos datos, podemos concluir que los universitarios estudiados, en su conjunto, son cautos y seleccionan a quienes (personas conocidas, amigos) y bajo qué premisas se exhiben en la red (cambian las opciones de privacidad, retocan las fotos, etc). Constatamos sin embargo diferencias por género. Las mujeres son más prudentes y cautas con la información que colocan en sus perfiles, resultando preocupante el número de hombres que admiten aceptar como amigo a un desconocido.

No podemos finalizar este apartado sin mostrar cómo hemos detectado entre el colectivo universitario un sentimiento que podríamos denominar de fatalismo, de indefensión. Entendido éste como la creencia de que es difícil poder controlar la información que sobre ellos se exhibe en las redes. Lo cual a veces les lleva a justificar ser más laxos con la información, disminuyendo la vigilancia y el control de la misma: "Si no lo puedo controlar no me voy a preocupar". "Sobre las fotos que no tengo control,... bueno, así es la vida". En la tabla I aparecen las respuestas dadas por el conjunto de encuestados a ítems relacionados con esta cuestión.

Este sentimiento de fatalismo puede servir de razonamiento para que muchos jóvenes justifiquen, tal vez por desconocimiento, desidia, dificultad u otras razones, el no actuar para controlar la información propia en la red, escudándose en la complejidad que ello supone.

\subsection{Elementos del perfil que sirven como indicadores perceptivos}

La interacción social en la red tiene características particulares, no necesitamos ver al otro para comunicarnos con él. El único indicador que tenemos de la imagen del otro es la representación que este hace de

\footnotetext{
6 La prueba Chi Cuadrado, con un grado de libertad, ha dado como resultado un valor de 6,02306E-07. Aceptando la significatividad cuando resulta menor de 0,0001 , con un margen de confianza del 99,5\%.
} 
su propia identidad. En la vida real el sujeto no decide voluntariamente su nombre, su sexo, edad, etc. En la red la realidad es distinta, el sujeto puede ser lo que quiere ser. Ya no es suficiente con sacar fotos, sino que es necesario distribuirlas inmediatamente. Subir una fotografía al Facebook o al Tuenti implica articular una relación con el otro. En esa foto se da a conocer parte de su vida y mediante ella se puede establecer un contacto con el otro. Antes, los factores que a uno le conferían el éxito o la aceptación en un grupo eran, por ejemplo, lo que decía, si resultaba ingenioso. En la actualidad podemos triunfar por las imágenes que cada cual presenta de sí mismo ante los demás.

Casi la totalidad de los jóvenes estudiados, tanto en las reuniones de grupo como en la encuesta (gráfico 4), coinciden en afirmar que "las fotografías" son el aspecto del perfil más visitado. Su importancia reside en la información que contienen, convirtiéndose en indicadores que les ayudan a inferir cualidades del otro observado. "Lo importante es si la persona te suena, si el ambiente te suena". Las fotografías les ayudan a contar historias (a dónde ha ido, qué ha visto, con quién se relaciona, en definitiva en qué entorno se mueven). Podríamos decir que la historia del autor de un perfil puede conocerse por su álbum.

Hay que tener en cuenta que, en principio, las fotografías son uno de los aspectos del perfil más difíciles de manipular. Es cierto que cada imagen individual que el sujeto sube se puede retocar. No obstante, la historia que cuenta el conjunto de las imágenes (algunas subidas por el sujeto u otras por sus amigos) que se muestra en un perfil es más difícil de controlar y nos da una idea de cómo es la vida de esa persona.

En relación con este punto, todos los participantes de las reuniones de grupo estaban de acuerdo en afirmar que los elementos de las fotografías en los que se fijan y que las hacen más o menos atractivas son, si resultan divertidas: "es importante que te hagan reír" y también si están cuidadas o retocadas. "Suelo ver si están retocadas, en sepia o en blanco y negro...etc. Esto indica que se aburre mucho o que quiere más visitas”.

Además, subir fotos también tiene una componente social. En las reuniones todos los participantes confirmaron que en torno a las fotografías se hace grupo, las fotos se comparten, cohesionan al grupo e incluso llenan su tiempo de ocio. "Cuando te sacas fotos es cuando haces algo en común”. Incluso la relación del grupo puede tener como finalidad llenar de contenido los perfiles, permitiendo desde puentes de comunicación entre los miembros hasta condicionar sus conductas. "Al final no me gustaba Tuenti ya que llegó un momento con mis amigas que, en lugar de divertirnos nos dedicábamos a sacar fotos para subirlas a Tuenti".

En relación al número de fotografías de los perfiles, investigadores como Ellison, Steinfield \& Lampe (2007) sugieren que el número de ellas en un perfil es el principal indicador del éxito social, sin embargo en nues- 
tra muestra este elemento no ha resultado relevante de cara a adquirir más popularidad (tabla II). Solo ha sido considerado como significativo por un porcentaje residual de entrevistados (7\%).

El resto de los elementos del perfil no tienen el peso de los anteriores, siendo en sí mismos un complemento a las imágenes. De entre ellos, el segundo en importancia es la información que escriben en el tablón, en el muro o lo que dice la frase de estado (57\%). El siguiente nivel en esta clasificación lo ocupa el contenido de los comentarios de otros en nuestro tablón/muro (53\% de acuerdo). En este sentido, en las reuniones manifiestaron que la importancia de estos últimos radicaba en que eran vistos como un indicador de popularidad, "muestra cuanta gente se interesa por ti". Indicadores como la edad o procedencia, son tenidas en cuenta por el $41 \%$ de los entrevistados. En último lugar se sitúan las frases o los grupos a los que se adhiere, así como la información sobre gustos que aparece en el mismo, con un acuerdo cercano al 30\% de entrevistados que manifiestan fijarse en ellos. Hay dos elementos del perfil a los cuales los jóvenes asignan un interés residual, como son la información profesional y la cantidad de comentarios.

Nuestros datos (tabla II) contradicen parcialmente las conclusiones a las que han llegado Lampe, Ellison \& Steinfield (2007), en relación a la importancia de los elementos del perfil. Mientras que para estos autores los elementos del perfil que pueden crear nexos entre los usuarios por su importancia de cara a crear y mantener relaciones sociales son los estudios, la universidad, etc..., en nuestra investigación podríamos decir que el análisis pormenorizado de las fotografías de los perfiles, es el que contribuye a crear las relaciones. Es posible que las diferencias se deban a cuestiones culturales.

En este punto hemos podido constatar que los contenidos de los perfiles también trabajan como mecanismos de proyección en los cuales nos vemos, nos comparamos con los demás y juzgamos el grado de similitud con nosotros. Al menos, así lo reconocen prácticamente 7 de cada 10 entrevistados (Gráfico 5). En las reuniones de grupo surgió esta cuestión en relación a las fotos del perfil. Para ellos la importancia de las fotos y la razón de más peso para mirar en primer lugar una imagen era: "Si crees que hay elementos en común contigo".

\subsection{Credibilidad de la información del perfil}

Una reflexión obligada al estudiar los perfiles de otros es la relativa al grado de credibilidad que asignan al contenido de los mismos. En las reuniones de grupo se observó cómo a los jóvenes, en general, la credibilidad de los perfiles no les preocupaba. A priori consideraban creíbles los perfiles de los demás, "no entiendo lo del mentir hasta dónde se puede llevar. Es muy difícil que tú puedas tener control sobre la mentira”. Los jóvenes universitarios estudiados no parece que se planteen, al observar un perfil, si su mentor miente o no. 
Por principio se diría que no, a juzgar por el número de entrevistados (66\%) para los cuales ni siquiera llega a ser una cuestión que les preocupe (gráfico 6).

También en las reuniones, en relación a esta cuestión, comentaban cómo a su juicio hay dos niveles de información en el perfil y, por tanto, la importancia de la veracidad de los contenidos varía en función de a qué nivel de información nos refiramos. Un primer nivel, el fundamental del perfil, son las fotografías, las imágenes que se suben tal y como en el apartado anterior hemos constatado. Un segundo nivel, complemento del anterior, lo constituyen el resto de los elementos del mismo. En este sentido, admiten que se pueda mentir en el perfil, en los elementos de este segundo nivel en aspectos como dónde has trabajado, a dónde quieres ir o incluso en una frase que suben al muro, ya que esta información compromete poco, no es la esencia de la imagen. "Hay gente que se pone nombre falso aunque el resto del perfil sea verdadero". Por el contrario, en las fotos es más difícil el engaño puesto que no solo dependen de lo que el sujeto escriba, además resulta difícil falsificar todas las fotografías que se suben. En la encuesta estas afirmaciones se confirman ya que para uno de cada dos entrevistados el perfil es un reflejo de cómo es la persona.

\section{Limitaciones}

Queremos dejar claras dos limitaciones que tiene este estudio. Una primera limitación del estudio tiene que ver con la naturaleza descriptiva de los resultados, lo que hace imposible estudiar relaciones causales entre las variables exploradas. En segundo lugar, debemos mencionar en relación a la muestra seleccionada (jóvenes universitarios de la Universidad del País Vasco) el alcance limitado de los resultados obtenidos con la misma; sería deseable poder contrastar nuestros resultados con muestras de otras universidades y áreas geográficas.

\section{Conclusiones}

Aunque los datos no son extrapolables al conjunto de los universitarios españoles usuarios de redes sociales, sí nos dan un indicio bastante sólido (el 84\% de la muestra inicial tenían Tuenti y/o Facebook) para afirmar que las redes constituyen una tendencia consolidada con una gran influencia en las vías de relación de este colectivo.

Los universitarios encuestados demuestran una clara preferencia por Tuenti, a la que consideran más sencilla, intuitiva, joven, más ágil y apropiada para relacionarse con sus amigos cercanos. Facebook, aun siendo referente en juegos y entretenimiento, tiene una imagen más formal, de producto más completo y de tener 
un público más amplio e internacional. La selección de la red en la que interactuar está en función del contacto u objeto de conversación.

Los jóvenes de la Universidad del País Vasco están preocupados y ocupados con la privacidad. La ejercitan llevando a cabo un control sobre los contenidos que exponen en las redes sociales. Son conscientes de lo que comparten y con quien lo comparten. No subir información íntima o cambiar las opciones de privacidad son las acciones que prácticamente la totalidad de ellos ejercita. Por sexo, las mujeres son más celosas de sus contenidos. Si bien tanto unos como otros, reconocen cierto fatalismo e impotencia, ante la dificultad de controlar el uso de su información en las redes.

Para ellos, no todos los elementos de información de su perfil tienen la misma importancia de cara a comunicar su imagen. Las fotografías son el elemento más relevante del mismo. El resto de los contenidos son simples complementos. De este modo, la percepción de la identidad virtual es construida, fundamentalmente, por las imágenes que uno presenta de sí mismo ante los demás.

Las fotos juegan un importante rol social. Compartiéndolas se alarga la experiencia del placer de estar con las personas que uno quiere. Otra razón del éxito de las imágenes es la confianza que en ellas se deposita en relación a la veracidad de las mismas, ya que consideran que en ellas es difícil el engaño. Sorprende que admitan posibles desviaciones en la credibilidad del resto de los elementos del perfil, a los que no dan importancia.

Para finalizar, cabe observar que este trabajo ha sido una primera toma de contacto, lo que significa no poder abarcar muchos de los aspectos del mismo. Entre ellos se puede señalar una tendencia, la egología virtual, entendida como la ciencia de ocuparse de uno mismo, de ocupar el terreno, de reforzarse, de revalorarse y de figurar por todos los medios posibles. ¿Qué mejor escenario que las redes sociales para lograrlo? Esto es lo que la autora Llucia Ramis (2010) denomina "egosurfing”. Se trata de un comportamiento similar al de quien se para a mirarse en los escaparates, una obsesión que parece afectar cada vez a más internautas, una especie de exhibicionismo en la red. Queremos que los demás nos busquen a nosotros, eso es el "egosurfing". Como confiesan los jóvenes en las reuniones de grupo, una de las ventajas de las redes es que les permite estar ahí. "Te sirve para estar en el candelero cuando ya no estás, para seguir estando en Madrid cuando llevas tiempo en Bilbao". En palabras de Ramis: "En las redes sociales no buscamos a los demás, quizás estamos allí para ampliar, hacer crecer y dar peso a nuestro yo". 
Gráfico 1. Imagen de las redes sociales Tuenti y Facebock

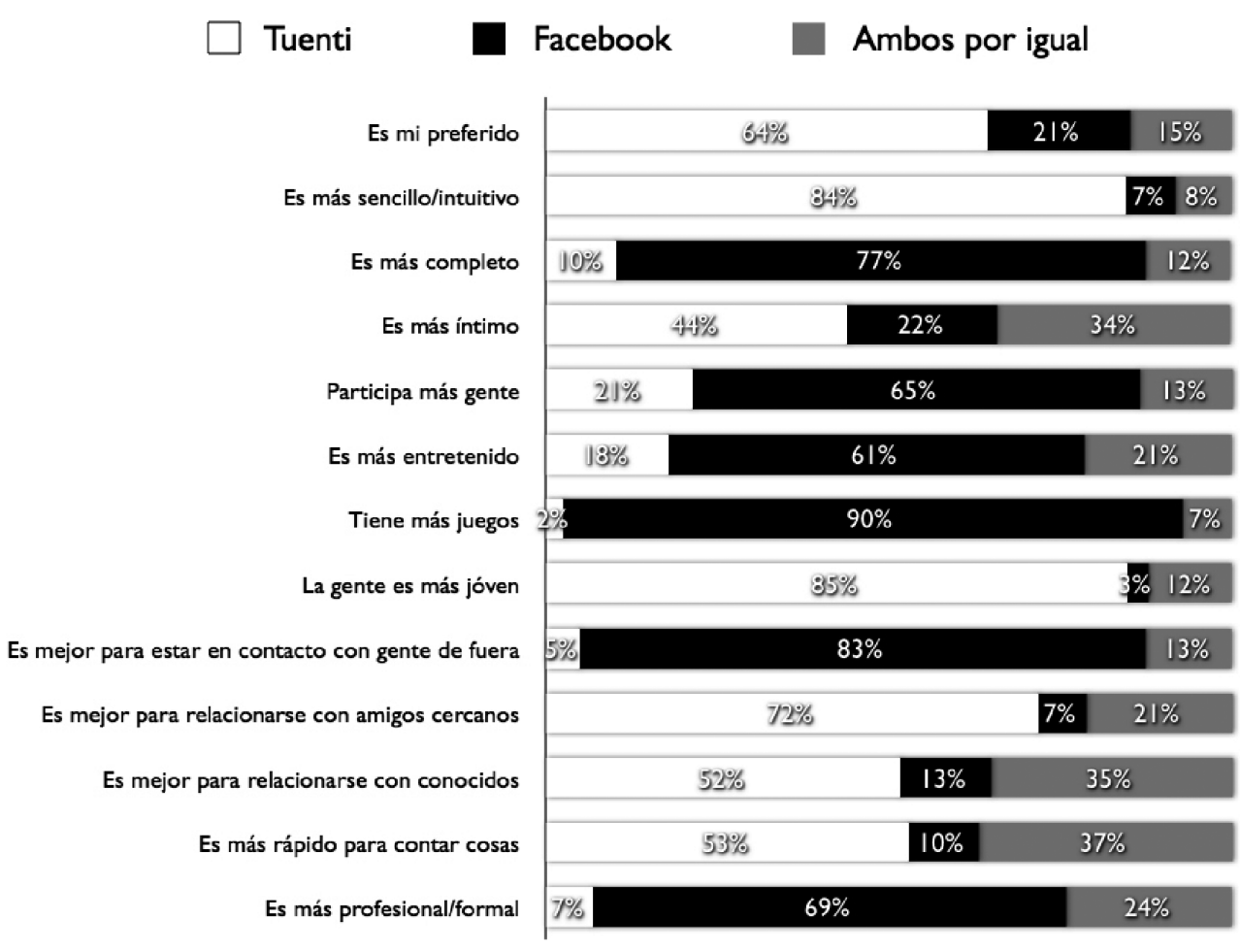

\section{Gráfico 2.}

Me preocupa lo que la gente pueda hacer con la información que de mi hay en la red

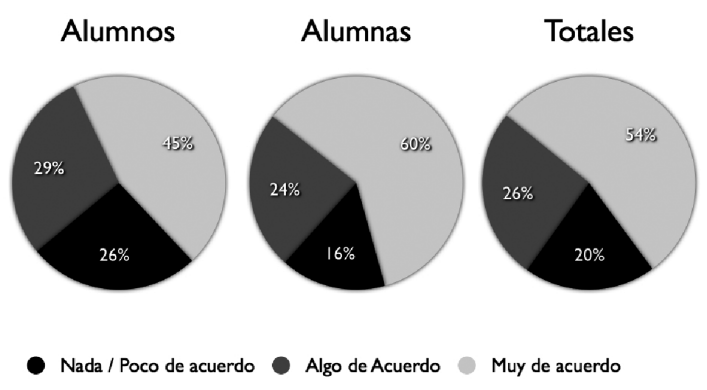




\section{Gráfico 3.}

Estrategias para mantener la privacidad en la red

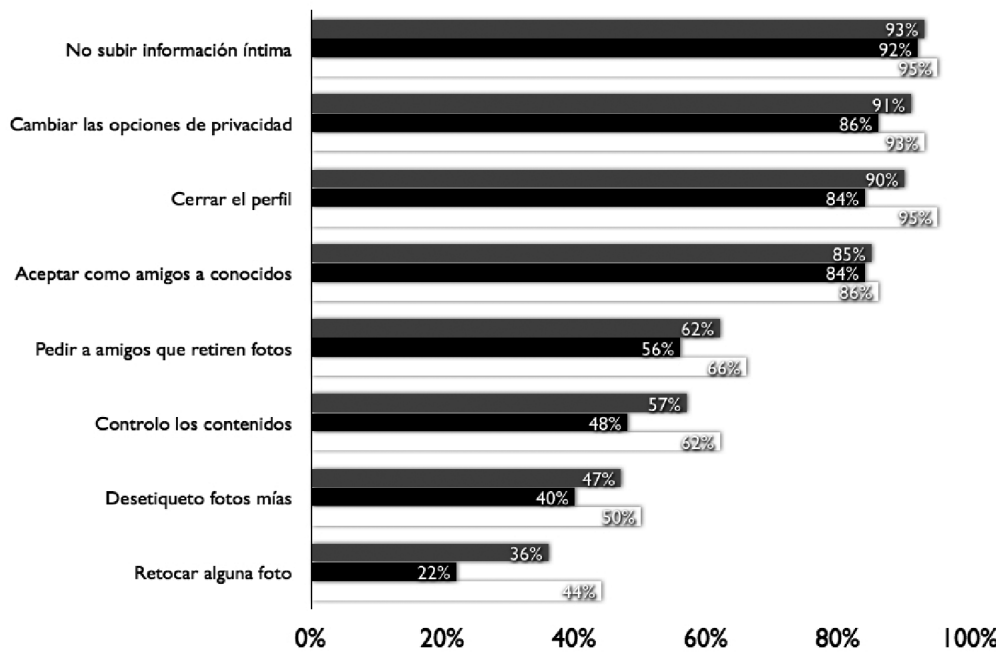

Gráfico 4. Elementos del perfil e importancia que asignan a los mismos.

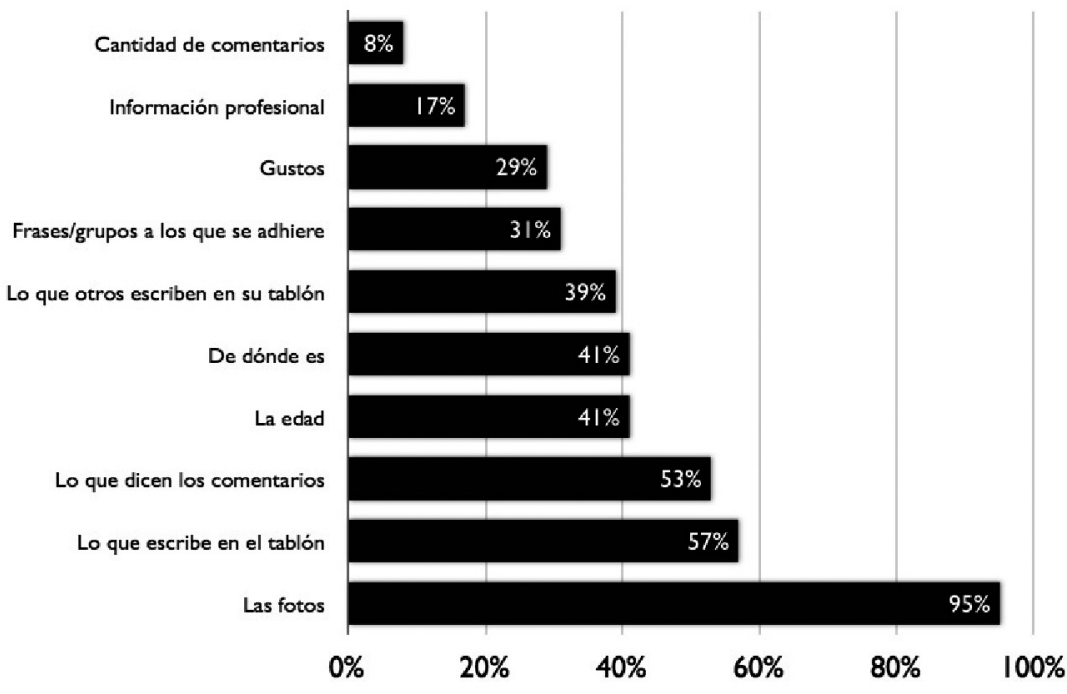


Gráfico 5. Me suelo fijar en los perfiles de otros para ver si hay elementos que coinciden con mis gustos

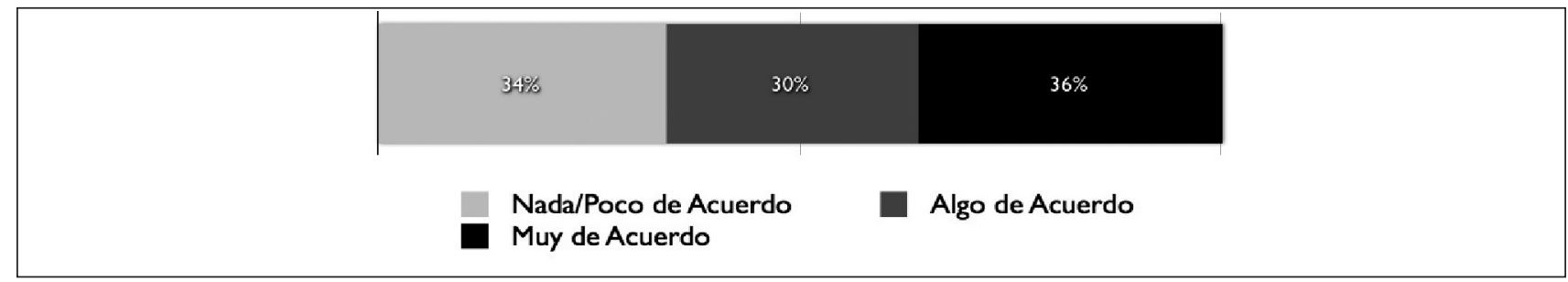

Gráfico 6. Credibilidad de los perfiles

\begin{tabular}{|c|c|c|}
\hline Viendo el perfil puedes hacerte una idea de como es una persona & $50 \%$ & $49 \%$ \\
\hline La gente suele mentir con lo que sube a la red & $30 \%$ & $70 \%$ \\
\hline Me preocupa que la gente mienta & $34 \%$ & $66 \%$ \\
\hline$\square$ Verdadero & & \\
\hline
\end{tabular}

Tabla I. Indicadores de fatalismo

\begin{tabular}{|lccc|}
\hline & Muy de acuerdo & Algo de acuerdo & En desacuerdo \\
\hline $\begin{array}{l}\text { Sé que no puedo controlar la imagen que se } \\
\text { ofrece de mí porque no depende sólo de lo } \\
\text { que yo publique. }\end{array}$ & $48 \%$ & $34 \%$ & $18 \%$ \\
\hline $\begin{array}{l}\text { Es muy difícil retirar un contenido que no } \\
\text { quieres que los demás vean }\end{array}$ & $35 \%$ & $27 \%$ & $48 \%$ \\
\hline
\end{tabular}

Tabla II. Capital social

\begin{tabular}{|lcc|}
\hline & Acuerdo & Desacuerdo \\
\hline La cantidad de comentarios de un perfil habla de lo popular que es esa persona & $8 \%$ & $65 \%$ \\
\hline Si alguien sube muchas fotos es un indicador de gran actividad social & $7 \%$ & $69 \%$ \\
\hline $\begin{array}{l}\text { Si son los amigos lo que suben muchas fotos sobre alguien, es un indicador de } \\
\text { actividad social }\end{array}$ & $12 \%$ & $57 \%$ \\
\hline
\end{tabular}




\section{ANEXO 2. Encuesta}

1. ¿Qué edad tienes?

2. Sexo: Chico Chica

3. ¿Tienes cuenta en alguna de estas dos redes sociales: Tuenti y/o Facebook?: Sí No

4. En tu opinión, cuál de las dos redes sociales se ajusta mejor a las siguientes frases (marca solo una de las tres opciones)

\begin{tabular}{|l|l|l|l|}
\hline & Tuenti & Facebook & Ambas por igual \\
\hline Es mi preferido & & & \\
\hline Es más sencillo/intuitivo & & & \\
\hline Es más completo & & & \\
\hline Es más íntimo & & & \\
\hline Participa más gente & & & \\
\hline Es más entretenido & & & \\
\hline Tiene más juegos & & & \\
\hline La gente es más joven & & & \\
\hline Es mejor para estar en contacto con gente de fuera & & & \\
\hline Es mejor para relacionarse con amigos cercanos & & & \\
\hline Es mejor para relacionarse con conocidos & & & \\
\hline Es más rápido para contar cosas & & & \\
\hline Es más profesional/formal & & \\
\hline
\end{tabular}


5. Marca tu grado de acuerdo con las siguientes frases

\begin{tabular}{|l|l|l|l|l|l|}
\hline & $\begin{array}{c}\text { Nada de } \\
\text { acuerdo }\end{array}$ & $\begin{array}{c}\text { Poco de } \\
\text { acuerdo }\end{array}$ & $\begin{array}{c}\text { Algo de } \\
\text { acuerdo }\end{array}$ & $\begin{array}{c}\text { Bastante de } \\
\text { acuerdo }\end{array}$ & $\begin{array}{c}\text { Muy de } \\
\text { acuerdo }\end{array}$ \\
\hline $\begin{array}{l}\text { Me preocupa lo que la gente pueda hacer con la } \\
\text { información que sobre mí hay en Tuenti/ } \\
\text { Facebook }\end{array}$ & & & & & \\
\hline $\begin{array}{l}\text { Es muy difícil retirar un contenido que no } \\
\text { quieres que los demás vean en Tuenti/Facebook }\end{array}$ & & & & & \\
\hline $\begin{array}{l}\text { Desetiqueto fotos mías subidas por otros en } \\
\text { las que no me gusta como aparezco }\end{array}$ & & & & & \\
\hline $\begin{array}{l}\text { Me preocupo de vigilar todos los contenidos } \\
\text { (fotos, comentarios...) que sobre mí se suben a } \\
\text { Tuenti/Facebook }\end{array}$ & & & & & \\
\hline $\begin{array}{l}\text { Creo que es mejor que mi perfil sea lo más } \\
\text { abierto posible }\end{array}$ & & & & & \\
\hline $\begin{array}{l}\text { Sé que no puedo controlar la imagen que se } \\
\text { ofrece de mí en Tuenti/Facebook porque no } \\
\text { depende solo de lo que yo publique }\end{array}$ & & & & & \\
\hline
\end{tabular}


6. En tu opinión, las siguientes frases son ¿iverdaderas o falsas?

\begin{tabular}{|l|l|l|}
\hline & Verdadero & Falso \\
\hline $\begin{array}{l}\text { Viendo su perfil de Tuenti/Facebook normalmente puedes hacerte una idea } \\
\text { de cómo es una persona }\end{array}$ & & \\
\hline En general, la gente no suele mentir con lo que sube a Tuenti/Facebook & & \\
\hline Me preocupa que la gente mienta en Tuenti/Facebook & & \\
\hline $\begin{array}{l}\text { Alguna vez les he pedido a mis amigos/as que retiren una foto en la que no } \\
\text { me gustaba como salía }\end{array}$ & & \\
\hline $\begin{array}{l}\text { He cambiado las opciones de privacidad de Tuenti/Facebook para limitar } \\
\text { quien accede a mis contenidos }\end{array}$ & & \\
\hline $\begin{array}{l}\text { Solo acepto como “amigos" de Tuenti/Facebook a personas que conozco } \\
\text { en persona }\end{array}$ & & \\
\hline He retocado algunas de las fotos que he subido a Facebook/Tuenti & & \\
\hline $\begin{array}{l}\text { He subido alguna vez a Tuenti/Facebook información íntima que fuera de la } \\
\text { red solo daría a conocer a unos pocos amigos de confianza }\end{array}$ & & \\
\hline
\end{tabular}

7. Cuando visito el perfil de alguien, sea un amigo, conocido o contacto, en lo que siempre me fijo es en:

- $\quad$ Las fotos (Sí/No)

- La información sobre gustos (Sí/No)

- $\quad$ La edad (Sí/No)

- $\quad$ La información profesional (Sí/No)

- $\quad$ Lo que dicen los comentarios (Sí/No)

- $\quad$ La cantidad de comentarios (Sí/No)

- $\quad$ De dónde es (Sí/No)

- $\quad$ Las frases/expresiones/grupos a los que se adhiere (Sí/No)

- Lo que dice la frase de estado/lo que escribe en el tablón/muro (Sí/No)

- $\quad$ Lo que otros le escriben en el tablón/muro (Sí/No)

$110\left|n^{\circ} 13\right|$ doxa.comunicación 
8. En qué medida estás de acuerdo con las siguientes frases:

\begin{tabular}{|l|l|l|l|l|l|}
\hline & $\begin{array}{l}\text { Nada de } \\
\text { acuerdo }\end{array}$ & $\begin{array}{l}\text { Poco de } \\
\text { acuerdo }\end{array}$ & $\begin{array}{c}\text { Algo de } \\
\text { acuerdo }\end{array}$ & $\begin{array}{c}\text { Bastante de } \\
\text { acuerdo }\end{array}$ & $\begin{array}{c}\text { Muy de } \\
\text { acuerdo }\end{array}$ \\
\hline $\begin{array}{l}\text { Creo que, si alguien sube muchas fotos, eso es } \\
\text { un indicador de que tiene gran actividad social }\end{array}$ & & & & & \\
\hline $\begin{array}{l}\text { Creo que si los amigos de alguien suben muchas } \\
\text { fotos sobre él/ella, es un indicador de gran } \\
\text { actividad social }\end{array}$ & & & & & \\
\hline $\begin{array}{l}\text { Pongo fotos atractivas de mi mismo en mi } \\
\text { perfil para incrementar las visitas a mi espacio }\end{array}$ & & & & & \\
\hline $\begin{array}{l}\text { Soy de los que opina que el número de } \\
\text { amigos en la red está relacionado con la } \\
\text { popularidad fuera de ella }\end{array}$ & & & & & \\
\hline $\begin{array}{l}\text { Me suelo fijar si en los perfiles de otros, hay } \\
\text { elementos (música, programas de tv, libros, etc) } \\
\text { que coinciden con mis gustos }\end{array}$ & & & & & \\
\hline
\end{tabular}

\section{Referencias bibliográficas}

Bacallao Pino, L. M. (2010): “Representaciones mediáticas de las redes sociales: un estudio de casos”, Revista Latina de Comunicación Social, 65, pp. 114-125. Universidad de La Laguna. [Consultado el 14/07/2010] http://www.revistalatinacs.org/ 10/art/887_UZaragoza/09_Lazaro_Bacallao.html

Back, M., Stofer, J., Varize, S., Gaddis, S., Schumukle, S., Egloff, B. and Gosling, S. (2010): "Facebook profiles reflect actual personality, not self-idealization", Psychological Science, XX: 1-3

Bringué, X. y Sábada, Ch. (2009): La generación interactiva en España. Niños y adolescentes ante las pantallas. Barcelona: Ariel.

- (2011): Menores y redes sociales, Colección Generaciones interactivas, n. 1.

Cervera, E. (2009): Lo que hacen tus hijos en Internet. Una guía para padres. Barcelona: RBA.

Cury, A. (2007): Padres brillantes maestros fascinantes. Barcelona: Zenith.

Debord, G. (1967): La sociètè du spectacle. Paris: Champ Libre. 
Ellison, N., Steinfield, C. \& Lampe, C. (2007): “The benefits of Faceboock friends: Social capital and collage students'use of online network sites", Journal of Computer- Mediated Communication, Vol. 12.

Fernández, S. (2008): “Redes sociales. Phenomenon palaver o reflejo del nuevo internauta”, Telos, n. ${ }^{\circ}$ 76, Julio-Septiembre, cuadernillo central.

Flores-Vivar, J. M. (2009): “Nuevos modelos de comunicación, perfiles y tendencias en las redes sociales”, Comunicar 33, pp. 73-81.

García, J. S. (2010): “Comportamientos activos en usuarios 2.0: Facebook supera a Tuenti, la red social que había sido líder en España. Causas, estrategias de comunicación e impacto en la recepción”, Observatorio (OBS*) Journal, vol. 4 -n. ํ2, pp. 153-166.

Hancock, J. y Toma C. L. (2009): "Putting your best face forward: the accuracy of online dating photographs", Journal of Communication, 59, pp. 367-386.

Garmendia, M., Garitaonandia, C., Martínez, G., Casado, M. A. (2011): Riesgos y seguridad en internet: La menores españoles en el contexto europeo. Bilbao: EU Kids Online (Universidad del País Vasco)

Lampe C., Ellison N. y Steinfield, C. (2007): "A familiar Faceboock: Profile elements as signals in an online social network", Proceedings. Online Representation of Self. California.

Livingstone, S. (2007): “Los niños en Europa. Evaluación de los riesgos en internet”, Telos, n. 73.

- (2008): “Taking risky opportunities in youthful content creation: teenagers' use of social networking sites for intimacy, privacy and self-expression", New Media \& Society, 10 (3), pp. 393-411.

Livingstone, S., Haddon. L. Gorzig, A y Olafsson, K. (2010): Risk and safety on the internet. The perspective of European Children. Initial finds. London: EU Kids Online.

Livingstone, S. y Helsper, E. (2010): "Balancing opportunities and risks in teenagers' use of the internet”, New Media \& Society, 12 (2), pp. 309-329.

Manago, A., Gram, Mb., Greenfield, PM., \& Salimkhan, G. (2008): “Self-presentation and gender on MySpace”, Journal of Applied Developmental Psychology, 29, pp. 446-458.

Miller, J. A. (1985): Extimidad. Buenos Aires: Paidós.

Monge, S.; Olabarri, E.: “Los alumnos de la UPV/EHU frente a Tuenti y Facebook: usos y percepciones”, Revista Latina de Comunicación Social, n. ${ }^{\circ}$ 66, pp. 079-100. http://www.revistalatinacs.org/11/art/925_UPV/04_Monge.html

Ramis, Ll. (2010): Egosurfing. Barcelona: Destino.

Sánchez Burón, A. y Fernández, M. a (2010): Informe Generación 2.0. Hábitos de los adolescentes en el uso de las redes sociales. Estudio comparativo entre Comunidades Autónomas. Universidad Camilo José Cela. http://www.slideshare.net/ucjc/ generacin-20-hbitos-de-los-ad [Consultado 22/07/2010] 
Sibila, P. (2008): La intimidad como espectáculo. Buenos Aires: Fondo de Cultura Económica.

The Cocktail Analysis (2008): Herramientas de comunicación online: Las Redes Sociales. http://www.tcanalysis.com/ 2008/11/13/the-cocktail-analysis-pone-en-marcha-el-observatorio-sobre-la-evolucion-de-las-redes-sociales/ [Consultado 12-06-2010]

- (2010): Informe de resultados Observatorio Redes Sociales. $2^{a}$ oleada http://tcanalysis.com/uploads/2010/02/ tca2a_ola_observatorio_redes_informe_publico.pdf [Consultado 11-06-2010].

- (2011): Informe de resultados Observatorio Redes Sociales. $3^{a}$ oleada http://www.tcanalysis.com/uploads/2011/02/Observatorio-RedesSociales2011.pdf [Consultado 18-07-2011].

Weisbuch, M., Ivcevci, Z y Ambady, N. (2009): "On being liked on the web and in the real World: consistency in first impressions across personal webpages and spontaneous behavior”, Journal of Experimental Social Psychology, n. ${ }^{\circ} 45$, pp. 573-576.

Zed Digital (2008): El fenómeno de las redes sociales. Percepción, usos y publicidad. http://www.zeddigital.es/Estudio\%20de\%20redes\%20sociales_20_11_2008.pdf [Consultado 15-07-2010]. 